\title{
Rubella antibody levels in school-aged children in Newfoundland: Implications for a two-dose rubella vaccination strategy
}

Samuel Ratnam PhD mph, Roy West msC PhD, Veeresh Gadag mSC PhD, Brett Williams bSC, Elizabeth OAtes RT

S RATNAM, R WEST, V GADAG, B WILLIAMS, E OATES. Rubella antibody levels in school-aged children in Newfoundland: Implications for a two-dose rubella vaccination strategy. Can J Infect Dis 1997;8(2):85-88.

OBJECTIVE: To determine the prevailing levels of rubella immunity among school-aged children who received a single dose of measles-mumps-rubella (MMR) vaccine at one year of age.

DESIGN: Cross-sectional study with a two stage cluster sampling of randomly picked schools across the province of Newfoundland.

STUDY POPULATION AND METHODS: A total of 1053, five to 17-year-old children were enrolled; vaccination history was verified through official records; and a sample of blood was taken. Rubella immunity was determined by enzyme immunoassay based on a serum antibody protective cut-off titre of more than 10 IU.

RESULTS: A total of $145(13.8 \%)$ were found to be nonimmune. The rate of susceptibility ranged from $3.2 \%$ to $25.9 \%$ for different age groups. The proportion susceptible was significantly higher at $16.5 \%$ in the age group eight to 17 years old versus $3.9 \%$ for the age group five to eight years old $\left(\chi^{2}=24.08 ; \mathrm{df}=1, \mathrm{P}<0.001\right)$. There was a significant regression of logarithm titre values on the age of children with an average decline in titre values of $8.1 \%$ per annum.

CONCLUSIONS: A substantial number of those who were given a single dose of MMR II vaccine may not have protective immunity against rubella as they reach prime reproductive age. There is a definite need to consider a two-dose rubella vaccination strategy in Canada, and these data suggest the second dose given after eight years of age will be most beneficial. In the move towards a routine two-dose measles vaccination strategy in Canada, the MMR II vaccine is being used for the second dose and given either at 18 months of age or at school entry. While this approach will have an overall beneficial effect, the impact of the above timing of the second dose on long term rubella immunity cannot be predicted at this time. These data also underscore the continuing need for prenatal rubella screening program.

Key Words: Rubella immunity, Rubella seroscreening, Rubella vaccination

Taux d'anticorps antirubéole chez les enfants d'âge scolaire à Terre-Neuve : implications d'une stratégie de vaccination à deux doses

OBJECTIF : Déterminer les taux d'immunité contre la rubéole qui prévalent chez les enfants d'âge scolaire qui ont reçu une seule dose de vaccin ROR à l'âge d'un an.

voir page suivante

The Newfoundland Public Health Laboratory, Department of Health and Division of Community Medicine, Faculty of Medicine, Memorial University of Newfoundland, St John's, Newfoundland

Correspondence and reprints: Dr S Ratnam, PO Box 8800, Newfoundland Public Health Laboratory, St John's, Newfoundland A1B 372.

Telephone 709-737-6568, fax 709-737-7070, e-mail nphlab@voyager.newcomm.net

Received for publication June 11, 1996. Accepted September 14, 1996 
MODÈLE : Étude transversale avec échantillonnage en grappe à deux phases provenant d'écoles choisies au hasard à Terre-Neuve.

POPULATION ÉTUDIÉE ET MÉTHODES : En tout, 1053 enfants de 5 à 17 ans ont été inscrits. Le carnet de vaccination a été vérifié au moyen des dossiers officiels et un prélèvement sanguin a été effectué. L'immunité contre la rubéole a été déterminée au moyen d'un immunodosage enzymatique sur la base des titres protecteurs seuils d'anticorps sériques de plus de 10 UI.

RÉSULTATS : En tout, 145 (13,8\%) individus se sont révélés non protégés. Le taux de sensibilité allait de 3,2 \% à 25,9 \% pour les différents groupes d'âge. Le taux de sujets sensibles était nettement plus élevé $(16,5 \%)$ chez les 8 à 17 ans que $(3,9 \%)$ chez les 5 à 8 ans $\left(\chi^{2}=24,08 ; \mathrm{df}=1, \mathrm{P}<0.001\right)$. On a noté une régression significative des titres logarithmiques d'après l'âge des enfants, avec un déclin moyen des titres de $8,1 \%$ par an.

CONCLUSIONS : Un nombre substantiel d'individus ayant reçu une seule dose de ROR II ne seraient peut-être pas protégés contre la rubéole lorsqu'ils arrivent à l'adolescence. Il faut envisager une stratégie de vaccination à deux doses contre la rubéole au Canada et ces données suggèrent que la deuxième dose soit administrée après l'âge de 8 ans pour être le plus efficace. Selon la tendance d'administrer une vaccination à deux doses contre la rougeole de routine au Canada, le vaccin ROR II est utilisé en deuxième dose et administré soit à l'âge de 18 mois ou au moment d'entrer à l'école. Cette approche aura un effet global bienfaisant, mais l'impact de cette synchronisation de la deuxième dose sur l'immunité à long terme contre la rubéole ne peut être prévisible pour l'instant. Ces données soulignent également la nécessité d'un programme de dépistage prénatal de la rubéole.

$\mathrm{T}$ here is renewed interest and resolve to eliminate indigenous measles and to control and eliminate indigenous rubella infection during pregnancy (1-3). Because measles, with its high infective potential and continuing outbreaks especially among previously vaccinated populations (4-6), attracts the major emphasis, a two-dose measles immunization strategy has gained support in recent years $(2,7)$. While there are recent epidemiological and laboratory data to support a two-dose strategy for the control and elimination of measles (3,8-10), there are insufficient data on the prevailing levels of immunity against rubella (1). It is well known that vaccine-induced immunity is lower than that resulting from natural exposure to the wild virus, and there are indications that vaccine-induced rubella immunity declines over time among those who received a single dose of measles-mumps-rubella (MMR) vaccine $(11,12)$. Because many of the current cohort of women of childbearing age have not been exposed to the wild rubella virus, the question concerning the level of protection against rubella infection among women of childbearing age has become an important and timely issue of public health significance (1). An increase in the incidence of rubella has been recognized in the United States (13), and congenital rubella continues to occur in both Canada and the United States $(14,15)$.

A recent Canadian consensus conference on rubella has set the goal to eliminate indigenous rubella infection during pregnancy by the year 2000 (1), coinciding with the goal to eliminate indigenous measles in North America (16). In an effort to achieve this goal, many provinces in Canada are now in the process of implementing a routine two-dose vaccination strategy that includes both measles and rubella (17). In addition, some provinces that are implementing a catch-up program have chosen to use a monovalent measles vaccine for this purpose (17). In the above context, a precise knowledge of the levels of rubella immunity in previously vaccinated schoolaged children would be useful in the overall consideration of whether to use both measles and rubella antigens in the two-dose strategy, the timing of the second dose and the rationale for continuing prenatal rubella screening program. In view of this, we carried out a cross sectional study of children from five to 17 years of age to obtain Canadian data on the prevailing levels of immunity against rubella among those who received a single dose of MMR II vaccine (Merck Sharp \& Dome, Pennsylvania) at one year of age.

\section{PATIENTS AND METHODS}

Study population: The study population comprised children in kindergarten to grade nine from five to 17 years of age. To obtain a provincial representation, children were enrolled through random selection of schools across the province of Newfoundland. A two-stage cluster sampling was done in each of five health regions. Three schools were picked at random in each health region, and up to four classes within each grade in a school were approached to enroll volunteers. (Random numbers were generated from the statistical software Minitab for Windows version 9 [Minitab, Pennsylvania]). Informed consent was obtained from all volunteers and their parents, and a sample of blood was obtained by venipuncture. MMR vaccination history was verified for all study subjects through official records maintained by the respective regional public health officials. (Childhood immunizations are mostly provided by public health services, and where physicians offer this service, the records are passed on to the public health registry). Test results were sent to all participants and the concerned public health units, and the children testing nonimmune were offered a second dose of MMR vaccine. This study was approved by the Human Investigation Committee, Faculty of Medicine, Memorial University of Newfoundland, St John's, Newfoundland.

Laboratory methods: Serum samples were stored at $-70^{\circ} \mathrm{C}$ until ready for testing for rubella antibodies. Rubella antibody was detected by Axsym Rubella IgG (Abbott laboratories, Illinois), a commercial quantitative enzyme immunoassay, and done in accordance with the manufacturer's instructions. A reading of greater than $10 \mathrm{IU}$ was considered to indicate protective immunity (18).

Statistical analyses: The estimated sample size was 1047. This sample size was adequate to detect a decline in titre of $4 \%$ per annum with equal number of children for all the ages from 5 to 17 years, at $5 \%$ level of significance and with $90 \%$ power. Regression analysis was used to study the relation between 
the titre levels and age of the children. $\chi^{2}$ test was used to study the association between protection level and each of the factors, age and sex.

\section{RESULTS}

Blood samples were available for testing from 1053 (543 males and 510 females; median age 10.5 years) of 1075 children enrolled. The number of children in each yearly cohort ranged from 89 to 148 for the age groups 6 to 14 years and was 47 for the five-year-olds and 27 for the 15 - to 17 -yearolds. All had received a single dose of MMR II vaccine at one year of age. Of the 1053 children, $15(1.4 \%)$ had no detectable rubella antibody titres (less than $1 \mathrm{IU}$ ), and an additional 130 (12.3\%) had titres between 1 and 10 IU. Therefore, based on the protective cut-off titre of $10 \mathrm{IU}$, a total of 145 (13.8\%) children were considered nonimmune to rubella. Among the 543 males the susceptibility rate was $13.6 \%$ and for the 510 females the corresponding figure was $13.9 \%$. The distribution of nonimmune by yearly cohort ranged from $3.2 \%$ to $25.9 \%$ (data not shown), with an increasing trend in older age groups (Table 1). Overall, the proportion susceptible reached $19.5 \%$ beyond 12 years of age. The overall proportion susceptible was significantly higher at $16.5 \%$ in the age group eight to 17 years as opposed to $3.9 \%$ for the age group five to eight years of age $\left(\chi^{2}=24.08 ; \mathrm{df}=1, \mathrm{P}<0.001\right)$. Significant differences in the proportion of susceptibles were also observed between different age groups for both males $\left(\chi^{2}=14.94 ; \mathrm{df}=3, \mathrm{P}<0.01\right)$ and females $\left(\chi^{2}=17.37 ; \mathrm{df}=3, \mathrm{P}<0.001\right)$. There was a significant regression of logarithm titre values on the age of the children with an average decline in titre values of $8.1 \%$ per annum.

\section{DISCUSSION}

Rubella vaccination was first introduced in Newfoundland in 1971. The trivalent MMR vaccine introduced in 1974 was replaced with MMR II vaccine in 1980 , and the policy has remained to give a single dose at 12 months of age. The current MMR vaccine coverage at school entry in Newfoundland is over $98 \%$. The most recent outbreaks of rubella in Newfoundland occurred in 1974 and 1975 and in 1986 and 1987. The 1986 and 1987 outbreak involved over 300 reported cases and was mostly limited to one health region (19). During the intervening periods and to date, the number of rubella notifications in the province had been minimal, ranging from none to eight per 100,000 population per year (provincial population 580,000 ).

Our earlier study of rubella immune status of Newfoundland children at four to six weeks and six months post-MMR II vaccination indicated a high rate of seroconversion and protective immunity to rubella in the range of over $98 \%(10,20)$. In a related study of school-aged children in Quebec, the proportion immune to rubella still remained quite high, in the range of $94 \%$ to $98 \%$ at five to six years post-MMR II vaccination (9). In a recent study of five-year-old British children, over $99 \%$ of vaccinees had protective immunity against rubella at four years post-MMR II vaccination (21). We also observed that the presence of afebrile upper respiratory tract infection at the time of MMR vaccination did not interfere with the
TABLE 1

Rubella antibody status in children five to 17 years of age who received a single dose of MMR II at one year of age

\begin{tabular}{|c|c|c|c|}
\hline \multirow{2}{*}{$\begin{array}{l}\text { Age group } \\
\text { (years) }\end{array}$} & \multirow{2}{*}{$\begin{array}{c}\text { Total number } \\
\text { of children } \\
\text { tested }\end{array}$} & \multicolumn{2}{|c|}{ Rubella immune status* } \\
\hline & & Susceptible (\%) & Immune (\%) \\
\hline 5 to 8 & 230 & $9(3.9)$ & $221(96.1)$ \\
\hline 8 to 11 & 327 & $46(14.1)$ & 281 (85.9) \\
\hline 11 to 14 & 380 & $66(17.4)$ & $314(82.6)$ \\
\hline 14 to 17 & 116 & $24(20.7)$ & $92(79.3)$ \\
\hline Total & 1053 & $145(13.8)$ & $908(86.2)$ \\
\hline
\end{tabular}

*Based on a protective cut-off titre of $>10 \mathrm{IU} \cdot \chi^{2}=27.67$; $d f=3$; $P<0.001$

response to the rubella component of the vaccine (22). In the present cross sectional study, for children up to eight years of age our result of $96.1 \%$ immunity against rubella is only slightly lower than that of the $98 \%$ to $99 \%$ immunity levels cited above for five- to seven-year-old children $(9,21)$. Beyond eight years of age, however, there is a clear indication of a sharp decline in the proportion immune (Table 1). In contrast to this, using the same children population in a related study dealing with measles vaccine-induced immunity, the level of protective immunity was found to be lower at $85.7 \%$ to start with at five years of age, and the proportion immune continued to decline thereafter (23). While the rate of decline in measles titre levels was $4.6 \%$ per annum (23), the corresponding rate of decline for rubella observed in the present study was $8.1 \%$. At this rate of decline in rubella titre levels, a sizable proportion of females reaching prime reproductive age is likely to have no protective immunity against rubella. Our data showed the overall proportion susceptible reaches close to $20 \%$ beyond 12 years of age among those previously immunized with a single dose of MMR II vaccine. It is worth noting that in a recent Swedish study, a steady decline in vaccine-induced rubella immunity was observed, with the proportion susceptible reaching $22 \%$ at 16 years postvaccination (11). Our observation in the present study is also substantiated by the data gathered in Newfoundland through our provincial prenatal rubella screening program. During the six-year period from 1990 to 1995 , women ages 14 to 19 years have accounted for $50 \%$ of those testing rubella nonimmune. The proportion susceptible to rubella in this age group has averaged 15\%, whereas for the screened pregnant women population as a whole the susceptibility rate averaged 5\% (unpublished data).

Our data and those of others $(11,12)$ indicate a declining level of protection against rubella in previously vaccinated populations, particularly as the female teenage population advances into the prime reproductive age group of 20 to 29 years, and thereby needs a second dose of rubella. In this context, it may be of interest to note that in a separate group of 45 children, five- to 17 -years-old, who were identified during this study as having received two doses of MMR II vaccine and who were studied separately, all had protective immunity against rubella (unpublished observation). Also, a large scale 
study of a two-dose rubella strategy in Sweden found 100\% seroconversion rate after a second dose in a population that had a susceptibility rate ranging from $41 \%$ to $57 \%$ after a single dose (12). However, the longevity of immunity against rubella following a second dose remains to be studied.

The questions concerning the need for a second dose of rubella vaccine, the timing of the second dose and occurrence of waning rubella immunity need to be addressed in the move to eliminate indigenous rubella infection during pregnancy in Canada (1). Our study shows that as many as $20 \%$ of young women from 12 to 17 years of age may be entering their childbearing years susceptible to rubella. Based on our data and those of others $(11,12)$, it may be concluded that there will be a greater number of Canadian women susceptible to rubella in the coming years. This should be of major public health concern. Obviously, the prenatal screening of women of childbearing age will partly alleviate this problem.

A better solution, however, would be a routine two-dose rubella vaccination strategy. With regard to the timing of the second dose for rubella, our data suggest that it will be most beneficial if given after eight years of age. There is consensus

\section{REFERENCES}

1. Mumps and Rubella Consensus Conference. Can Commun Dis Rep 1994;20:165-76.

2. Consensus conference on measles. Can Commun Dis Rep 1993;19:72-9.

3. Atkinson WL, Orenstein WA, Krugman S. The resurgence of measles in the United States, 1989-1990. Ann Rev Med 1992;43:451-63.

4. National Vaccine Advisory Committee. The measles epidemic. The problems, barriers, and recommendations. JAMA 1991;266:1547-52.

5. Katz SL, Gellin BG. Measles vaccine: Do we need new vaccines or new programs? Science 1994;265:1391-2.

6. Orenstein WA, Markowitz L, Atkinson WL, Hinman AR. Worldwide measles prevention. Isr J Med Sci 1994;30:469-81.

7. Immunization Practices Advisory Committee. Measles prevention: Recommendations of the Immunization Practices Advisory Committee (ACIP). MMWR 1989;38:S-9,1-13.

8. Emdonson MB, Addiss DG, McPherson JT, et al. Mild measles and secondary vaccine failure during a sustained outbreak in a highly vaccinated population. JAMA 1990;263:2467-71.

9. Boulianne N, De Serres G, Ratnam S, Ward BJ, Joly JR, Duval B. Measles, mumps, and rubella antibodies in children 5-6 years after immunization: Effect of vaccine type and age at vaccination. Vaccine 1995;13:1611-6.

10. Ratnam S, West R, Gadag V, Burris J. Measles immunization strategy: Measles antibody response following MMR II vaccination at one year of age of children. Can J Public Health 1996;87:97-100.

11. Christenson B, Böttiger M. Long-term follow-up study of rubella antibodies in naturally immune and vaccinated young adults. Vaccine 1994;12:41-5.

12. Christenson B, Böttiger M. Changes of the immunological patterns against measles, mumps and rubella. A vaccination programme studied 3 to 7 years after the introduction of a two-dose schedule. Vaccine 1991;9:326-9.

13. Increase in Rubella and Congenital Rubella Syndrome - United States, 1988-1990. MMWR 1991;40:93-9. for a routine two-dose measles vaccination strategy in Canada, and this is being implemented in some provinces $(2,17)$. The trivalent MMR II vaccine is routinely used for the second dose in these provinces, and given either at 18 months or at school entry (17). (Our studies dealing with measles vaccination strategy has indicated 18 months as the most appropriate age for a second dose of measles vaccine if the first dose continues to be given at 12 months of age [24]). Our data clearly support the use of a bivalent measles-rubella vaccine or trivalent vaccine such as MMR II rather than a monovalent measles vaccine for the second dose. However, the impact of the above timing of the second dose on long term rubella immunity cannot be predicted at this time. Also, in the above context, the use of monovalent measles vaccine for 'catch-up' programs for school-aged children (17) may need to be reassessed. Further studies following a two-dose MMR II vaccination scheduled either at 18 months or school entry are needed to assess the impact of this strategy on long term rubella immunity. In the meantime, our data underscore the need to continue prenatal rubella screening programs and immunization of those who are found susceptible.

14. Valiquete L, Saintonge F, Carsley J, et al. Survey of congenital rubella syndrome, Montreal, Laval, and Montérégie, Quebec, 1985-1991. Can Commun Dis Rep 1996;22:33-5.

15. Lee SH, Ewert DP, Frederick PD, Mascola L. Resurgence of congenital rubella syndrome in the 1990s. JAMA 1992;267:2616-20.

16. Health Canada. National Advisory Committee on Immunization: Supplementary statement on measles elimination in Canada. Can Commun Dis Rep 1996;22:9-15.

17. Laboratory Centre for Disease Control. Provinces implementing the routine two-dose measles vaccine and supplementary catch-up program. Measles Update 1996;4:1-2.

18. National Committee for Clinical Laboratory Standards (NCCLS). Evaluation and Performance Criteria for Multiple Component Test Product Intended for the Detection and Quantification of Rubella IgG Antibody: Tentative Guideline, NCCLS Document 1/LA6-T. Villanova: NCCLS, 1992.

19. Ratnam S, Stratton F. An ongoing epidemic of rubella Newfoundland and Labrador. Can Dis Wkly Rep 1987;13:119-21.

20. Ratnam S, Chandra R, Gadag V. Maternal measles and rubella antibody levels and serologic response in infants with MMR II vaccine at 12 months of age. J Infect Dis 1993;168:1596-8.

21. Miller E, Hill A, Morgan-Capner P, Forsey T, Rush M. Antibodies to measles, mumps and rubella in UK children 4 years after vaccination with different MMR vaccines. Vaccine 1995;13:799-802.

22. Ratnam S, West R, Gadag V. Measles and rubella response after measles-mumps-rubella vaccination in children with afebrile upper respiratory tract infection. J Pediatr 1995;127:432-4.

23. Ratnam S, West R, Gadag V, Williams B, Oates E. Immunity against measles in school aged children: Implications for measles revaccination strategies. Can J Public Health 1996;87:407-410.

24. Ratnum S, West R, Gadag V. When to vaccinate. Wiping out measles. Can Med Assoc J 1997;156:979,982. 


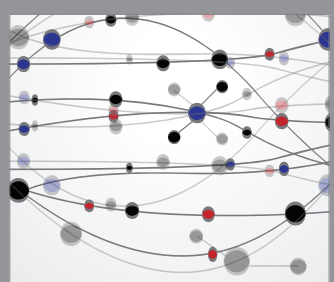

The Scientific World Journal
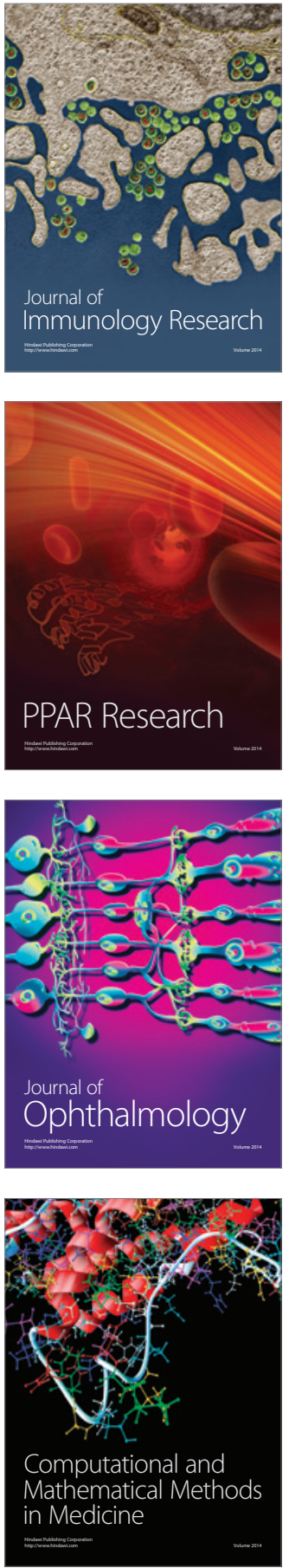

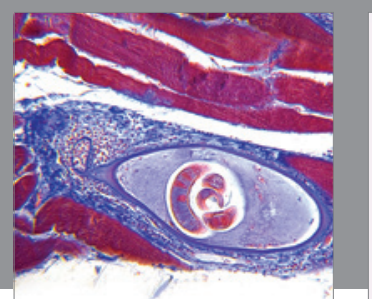

Gastroenterology Research and Practice

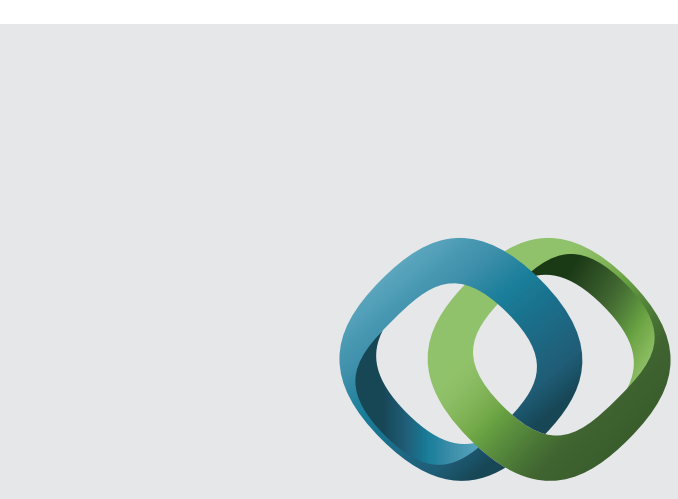

\section{Hindawi}

Submit your manuscripts at

http://www.hindawi.com
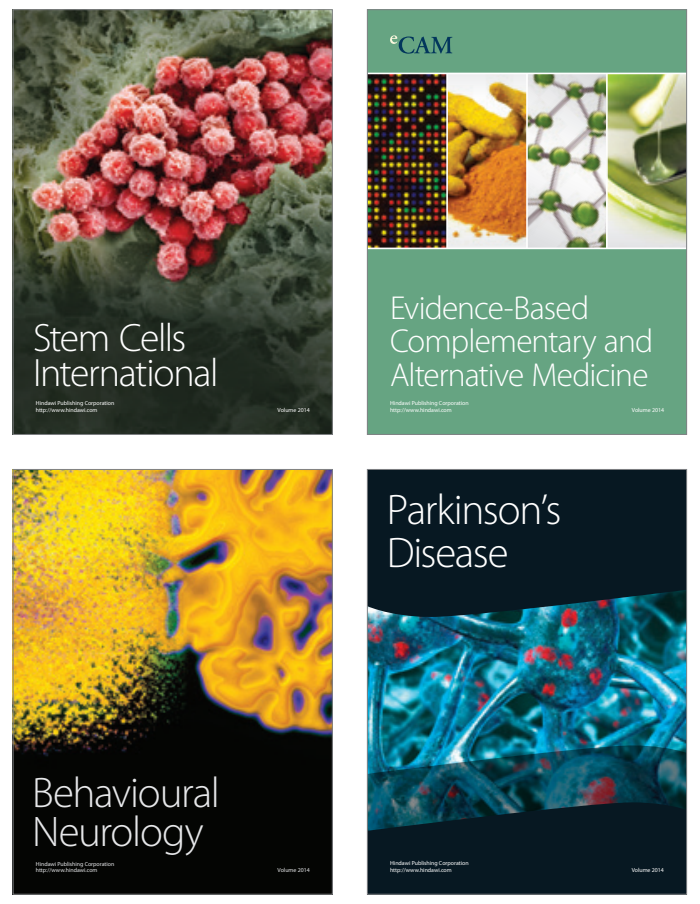
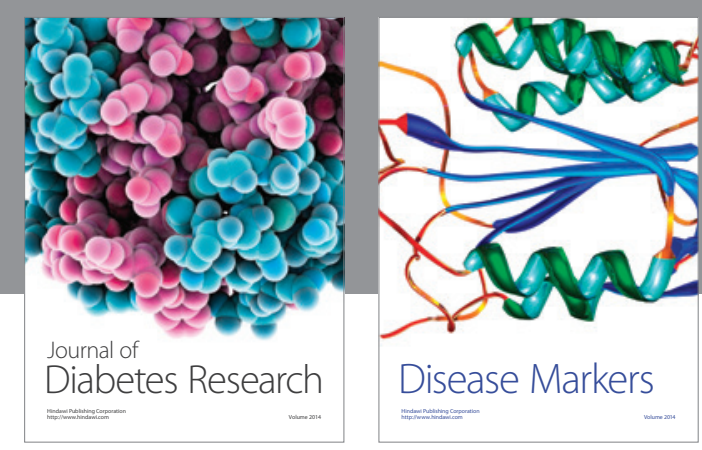

Disease Markers
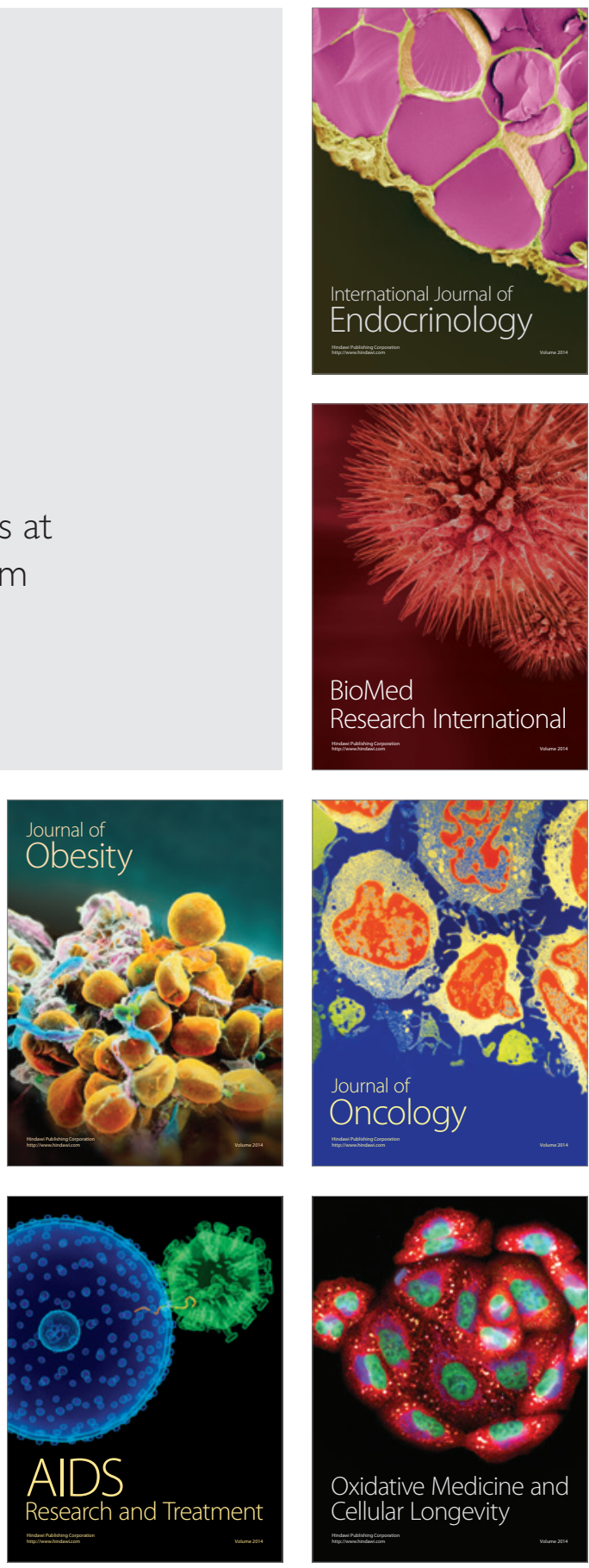